\title{
Thyroid hormones and their receptors in the regulation of cell proliferation
}

\author{
Monika Puzianowska-Kuznicka ${ }^{1,2 \bowtie}$, Maciej Pietrzak ${ }^{1}$, Olga Turowska ${ }^{2}$ \\ and Alicja Nauman ${ }^{2}$ \\ ${ }^{1}$ Department of Endocrinology, Medical Research Center, Polish Academy of Sciences, Warszawa, Poland; ${ }^{2}$ De- \\ partment of Biochemistry and Molecular Biology, Medical Center of Postgraduate Education, Warszawa, Poland; \\ 凶e-mail: monika@amwaw.edu.pl
}

Received: 25 October, 2006; revised: 07 November, 2006; accepted: 08 November, 2006 available on-line: 19 November, 2006

\begin{abstract}
In the present work, we have reviewed data showing that triiodothyronine and its nuclear receptors modify expression of different genes/proteins involved in cell cycle control beginning from growth factors (such as EGF and TGF- $\beta$ ), to cell surface receptors (EGFR), as well as proteins acting at the cell membrane (Ras), various transcription factors (c-Fos, c-Myc, E2F1), cyclins, Cip/Kip family of cdk2 inhibitors, and p53 inhibitor Mdm2 (Table 1). We have shown how TRs are also able to modify the fate of a cell, thanks to their ability to form complexes with other transcription factors such as p53 - a key regulator of apoptosis and proliferation. Available data show that the function of thyroid hormones and of their receptors on cell proliferation is not homogenous. In fact, it strongly depends on the cell type, its developmental state (progenitor or differentiated), its patho-physiological state (normal or tumor cell), and the so-called 'cellular context'. Therefore, it is not possible to uniformly recommend T3 treatment or T3 depletion to stop or initiate proliferation of all cell types. Instead, a very individual and careful action should be considered.
\end{abstract}

Keywords: proliferation, triiodothyronine (T3), thyroid hormone nuclear receptors (TRs), mitogens, oncoproteins

\section{INTRODUCTION}

Thyroid hormones regulate cellular metabolic activity and co-regulate cell proliferation, apoptosis, and differentiation. Their crucial role in embryonic development, especially of the central nervous system and musculoskeletal system, is well established (Williams et al., 1998; Morreale de Escobar et al., 2004; Bernal, 2005). There is a growing body of evidence that disturbed triiodothyronine (T3)-dependent control of cellular processes plays a role in tumorigenesis (Yen \& Cheng, 2003; Cheng, 2004; 2005). However, the data regarding T3 influence on proliferation is scattered in different publications and no concise summary on this subject has been published. In this article we present the current state of knowledge regarding confirmed and potential mechanisms by which thyroid hormones might influence cell proliferation. First, we offer a short description of the cell cycle with a special emphasis on the control of the progression from $G_{1}$ to $S$ phase, and then we present the principles of T3 action at the molecular level. Finally, we present the genes and proteins involved in the cell cycle control that are under the influence of $\mathrm{T} 3$, and based on the available data we describe proposed mechanisms of their regulation by this hormone.

\section{THE CELL CYCLE AND ITS MAJOR REGULATORS AND EXECUTORS}

The cycle of the somatic cell consists of mitosis $(\mathrm{M})$, gap $1\left(\mathrm{G}_{1}\right)$, DNA synthesis $(\mathrm{S})$, and gap 2

Abbreviations: ATF, activation transcription factor; CRE, cyclic AMP response element; CREB, CRE-binding protein; EGF, epidermal growth factor; EGFR, EGF receptor; RB, retinoblastoma protein; RXR, retinoid X receptor; SRE, serum response element; TR, thyroid hormone nuclear receptor; TREs, thyroid hormone response elements; T3, triiodothyronine; T4, thyroxine. 
Table 1. The summary of the influence of triiodothyronine treatment on the regulation of the genes/proteins involved in proliferation control

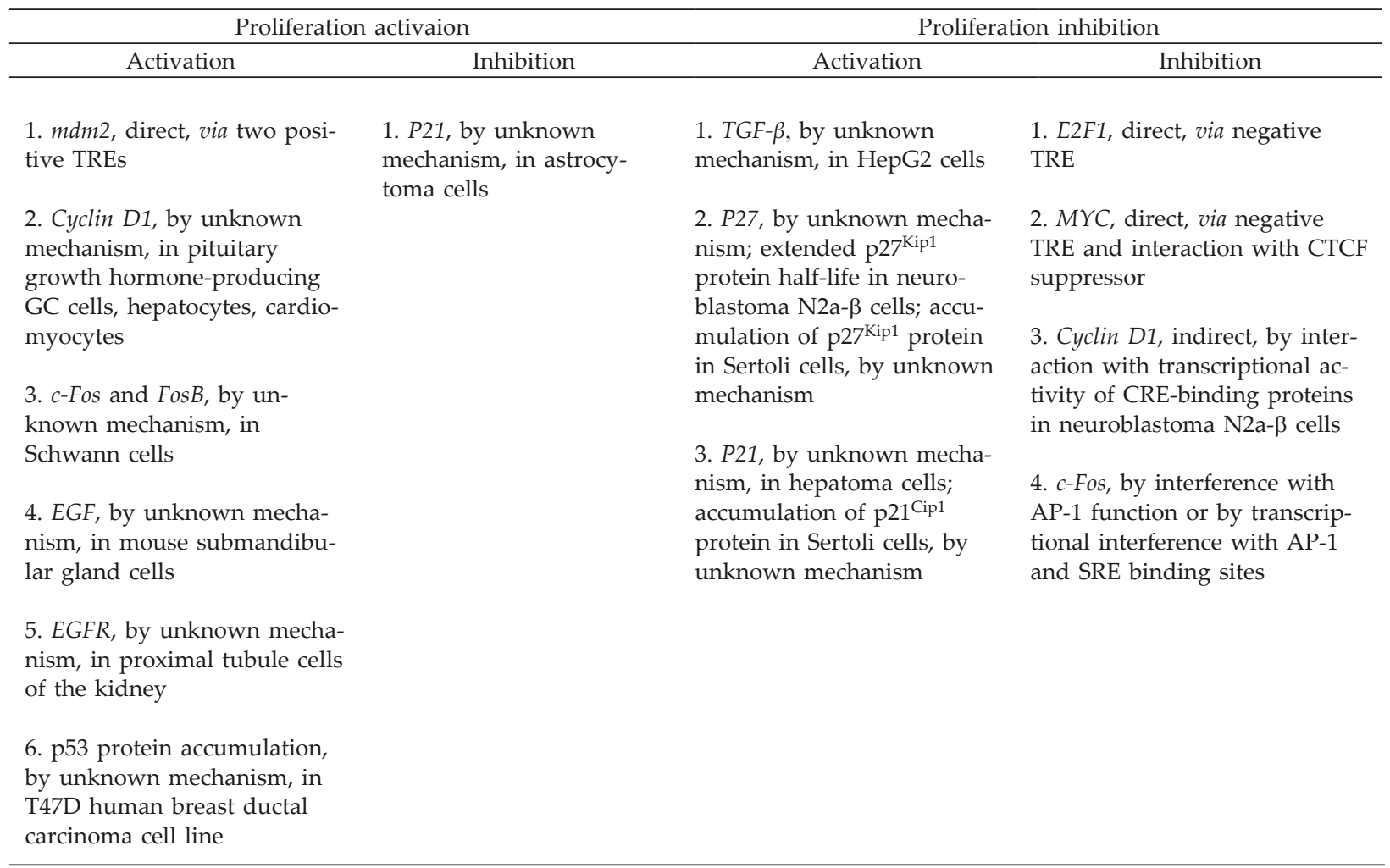

$\left(G_{2}\right)$ phases (Fig. 1). The cell responds to both mitotic and antiproliferative signals from the end of mitosis until it reaches restriction point 'of no return' $(R)$ at the end of $G_{1}$ phase. In response to mitogenic signals cyclins D1, D2, and D3 (Sherr, 1993; Sherr \& Roberts, 2004) form complexes with cyclindependent kinases cdk4 or cdk6 (Matsushime et al., 1992; Meyerson \& Harlow, 1994). While cdk4 and cdk6 are quite stable, cyclins D are short-lived pro-

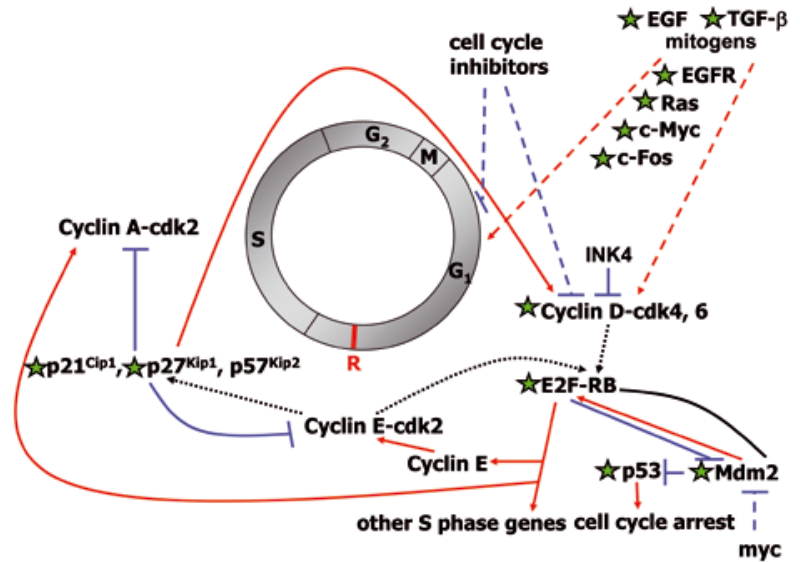

Figure 1. Simplified scheme of the cell cycle and selected proteins involved in the control of the cycle.

Red arrows, activation; blue lines, inhibition; black dotted arrows, phosphorylation; green star, place of triiodothyronine/thyroid hormone nuclear receptors action; $r$, restriction point. teins, and their synthesis and activity are dependent on the persistent presence of mitogens. The cyclin D-cdk4, -cdk6 complexes initiate the phosphorylation of retinoblastoma protein (RB) (Harbour et al., 1999) bound to E2F transcription factors (Attwooll et al., 2004). Upon RB phosphorylation the activatory members of E2F family are released from RB-E2F complexes and activate a number of target genes including cyclin E, cyclin $A$ and other genes (Geng et al., 1996; Helin et al., 1998) necessary for cell cycle progression from the $G_{1}$ to the $S$ phase $(\mathrm{Wu}$ et al., 2001). Cyclin E forms a complex with cdk2 which completes RB phosphorylation. Once the cell enters $S$ phase, cyclin E is degraded and the released cdk2 forms a complex with cyclin A.

The action of cdk2 but not of cdk 4 and $\operatorname{cdk} 6$ is inhibited by Cip/Kip family members (that includes $\mathrm{p} 21^{\mathrm{Cip} 1}$, p27 ${ }^{\mathrm{Kip} 1}$, p57 ${ }^{\mathrm{Kip} 2}$, among others). The presence of Cip/Kip family members is also required for the assembly of cyclin D-cdk4, -cdk6 complexes, while absence of free Cip/Kip proteins is necessary for cyclin E-cdk2 activation and cell cycle progression through the $G_{1}$ phase. In addition, cyclin Ecdk2 phosphorylates $\mathrm{p} 27^{\mathrm{Kip} 1}$, targeting it for ubiquitination and degradation (Sherr, 2000; Vidal \& Koff, 2000). Other cdk inhibitors are proteins belonging to INK4 family that oppose the activity of cyclin D-dependent kinases. INK4 proteins sequester $\mathrm{cdk} 4$ and cdk6 facilitating the release of Cip/Kip proteins that then inhibit cyclin E-cdk2 complexes leading to cell 
cycle arrest (Sherr \& Roberts, 1999; Vidal \& Koff, 2000).

\section{THE PRINCIPLES OF THYROID HORMONE ACTION AT THE MOLECULAR LEVEL}

Triiodothyronine (T3), the most active form of thyroid hormone is mainly produced by extra-thyroidal tissues via deiodination of the outer ring of thyroxine (T4) (Bianco et al., 2002). Even though thyroid hormones can act via non-genomic mechanisms (Bassett et al., 2003), they exert their function mostly by interacting with thyroid hormone nuclear receptors (TRs). TRs are transcription factors that regulate activity of T3-target genes in a ligand-dependent manner. They are protein products of TRA and TRB genes that, in humans, are located on chromosome 17 and 3, respectively. Alternative splicing and the use of alternative promoters result in the production of a number of receptor isoforms including TR $\alpha 1$ and TR $\alpha 2$, as well as TR $\beta 1$ and TR $\beta 2$ main isoforms (Cheng, 2000; Weiss \& Ramos, 2004). TR isoforms, although present in almost all human tissues, are differentially expressed (Sakurai et al., 1989; Shahrara et al., 1999).

Therefore, the biological effect of T3 in a given tissue depends on a number of factors: the amount of bioavailable hormone, the levels of different TR isoforms (Cheng, 2000; 2005), and post-transcriptional modifications of TRs (Chen et al., 2003; Lin et al., 2005), the type of their heterodimerization partners - retinoid X receptors (RXRs) (Rastinejad, 2001; Szanto et al., 2004), the interaction with co-repressors and co-activators (Chen \& Evans, 1995; Onate et al., 1995; McKenna et al., 1999; Manteuffel-Cymborowska, 1999; Cheng, 2000; Sadow et al., 2003), and on the structure of thyroid hormone response elements (TREs) in the promoters of target genes.

TREs present in T3-activated promoters are known as 'positive' TREs, while TREs present in the promoters inhibited by this hormone are considered 'negative'. Consensus, ideal 'positive' TREs consist of two AGGT(C/A)A hexamers separated by four neutral base pairs (direct repeat TRE-DR4). Such hexamers can also be arranged as inverted palindromes separated by six neutral base pairs (TRE-IP6), or as palindromes with no additional base pairs (TRE-P0) (Schrader \& Carlberg, 1994). TRs can bind to DNA both in the absence, and in the presence of T3. TR/ RXR heterodimer bound to 'positive' TRE in the absence of T3 recruits a co-repressor complex that contains histone deacetylase, among others. This enzyme removes acetyl groups from certain histones, thus stabilizing chromatin structure and making it inaccessible for transcriptional activators. This results in the inhibition of gene transcription below the basal (T3 and TR-independent) level (Wolffe et al., 2000; Zhang \& Lazar, 2000; Eckey et al., 2003; Moore \& Guy, 2005). In the presence of the hormone the structure of TR changes, forcing co-repressors to dissociate, and allowing co-activators to bind. Co-activator complexes contain another chromatin structure-modifying enzyme, histone acetyltransferase, that remodels chromatin, making it accessible for other transcription factors. This causes the increase of gene transcription markedly above the basal level (Wolffe et al., 2000; Zhang \& Lazar, 2000; Moore \& Guy, 2005).

The CAAAG(T/C) sequence creates a best described 'negative' TRE, a so-called z-element (Carr \& Wong, 1994; Sasaki et al., 1999; Shibusawa et al., 2003). The gene containing the 'negative' TRE within its promoter bound by unliganded TR is activated, while bound by T3-TR complex is inhibited (Chatterjee et al., 1989; Carr \& Wong, 1994; Radoja et al., 1997; Nygard et al., 2003).

\section{THE DIVERSE INFLUENCES OF TRIIODOTHYRONINE ON PROLIFERATION}

The first clues for a role of thyroid hormones in the regulation of cell proliferation came from the observations, at the beginning of XX Century, of amphibian metamorphosis. Metamorphosis is strictly and exclusively controlled by T3. Three types of changes take place during this process: complete involution of some organs, remodeling of others, and de novo development of a new ones. On the cellular level, these changes are caused by a combination of apoptosis and cell proliferation (Su et al., 1999).

The result on proliferation of treatment with T3 depends on the cell/tissue type and its developmental state. For example, T3 activates proliferation of hepatocytes after partial hepatectomy and is, in fact, considered a primary liver mitogen (Francavilla et al., 1994; Malik et al., 2003). It also accelerates wound healing of the skin (Safer et al., 2005), induces proliferation of cultured bovine thyroid cells (Di Fulvio et al., 2000), of bone marrow pro-B cells (Foster et al., 1999), of pancreatic acinar cells (Ohmura et al., 1997; Ledda-Columbano et al., 2005), and of renal proximal tubular epithelial cells (Ohmura et al., 1999). Finally, it increases DNA synthesis in osteoblasts (Kassem et al., 1993), and in other cells. On the other hand, T3 treatment blocks proliferation and induces differentiation of oligodendrocyte progenitor cells (Baas et al., 1997), of neuroblastoma N2a- $\beta$ cells (Garcia-Silva et al., 2002), and of erythroid progenitors (Bauer et al., 1998); it also prevents cycling of postnatal Sertoli cells (Palmero et al., 1995; Holsberger et al., 2003), as well as of mammary epithelial cells (Gonzales-Sancho et al., 2002). 


\section{DIRECT REGULATION BY T3 OF THE GENES ENCODING PROTEINS INVOLVED IN THE CONTROL OF PROLIFERATION}

E2F1

E2F1 encodes one of key regulators of proliferation, the E2F1 protein belonging to the family of E2F transcription factors (Attwooll et al., 2004). Classic members of E2F family form three groups: transcriptional activators (E2F1-3) that induce $S$ phase entry (Johnson et al., 1993; Wu et al., 2001), transcriptional suppressors (E2F4-5), and the E2F6 repressor that does not bind pocket proteins (RB, p107 or p130). E2F1 released from the inhibitory complex with $R B$ protein activates transcription of a number of target genes including genes for cyclin E, cyclin A, cdk2, and others (Geng et al., 1996; Helin, 1998) that results in cell cycle progression via the ' $\mathrm{R}$ ' restriction point.

It has been shown that treatment of embryonic carcinoma cells and of oligodendrocyte precursor cells with T3 decreases their proliferation rate by arresting cells in the $G_{1}$ and $S$ phases, but this effect was dependent on the presence of active TRs. This was accompanied by a rapid downregulation of E2F1 mRNA and of protein levels. A negative TRE resembling those present in TSH promoters was found in E2F1 promoter (-200 to -195 bp relative to transcription start site). Transactivation assays showed that TR bound to this TRE activated transcription in the absence of T3 and repressed it in the presence of the hormone (Nygard et al., 2003). The level of E2F1 promoter activity was dependent on the concentration of T3 (Turowska et al., unpublished). In addition, some dominant-negative TR mutants cloned from human cancers (Kamiya et al., 2002; PuzianowskaKuznicka et al., 2002) activated E2F1 promoter both in the absence, and in the presence of T3, suggesting the role for such mutants in the deregulation of cell proliferation in cancer tissues (Turowska et al., unpublished).

\section{MYC}

c-Myc functions as one of the key downstream effectors of most mitogenic signals (Cole \& Nikiforov, 2006). In normal cells, the expression of MYC gene is under tight control of growth factor-dependent signals, while in cells with deregulated MYC control proliferation often takes place in the absence of external stimuli (Bernard \& Eilers, 2006). c-Myc protein is a transcription factor that regulates expression of distinct sets of target genes. Transcriptional activation by c-Myc is mediated by
c-Myc/Max dimers binding to $\mathrm{CA}(\mathrm{C} / \mathrm{T}) \mathrm{GTG}$ (the Ebox) consensus sequence, while transcriptional inhibition is mediated through distinct DNA elements (Amati et al., 2001).

Treatment with T3 of neuroblastoma N2a$\beta$ cells overexpressing active TR $\beta 1$ led to a rapid downregulation of MYC gene accompanied by the decrease of the amount of c-Myc protein (PerezJuste \& Aranda, 1999). A negative TRE arranged as an inverted palindrome separated by three neutral base pairs has been found within the first exon of the mouse $c-m y c$ gene. This TRE lies next to the binding site for CCCTC binding factor (CTCF) that acts as transcriptional repressor. TR bound to its recognition site interacts physically with CTCF both in the absence, and in the presence of T3, interfering with CTCF function. Moreover, the negative TRE lies within the region of RNA polymerase pausing and release. This suggests the involvement of TR bound to its own recognition site in premature termination of transcription from $c-m y c$ gene (Perez-Juste et al., 2000), a hypothesis which was indeed confirmed (Garcia-Silva et al., 2002). The regulation of $c-m y c$ gene might require the presence of different TR isoforms, at least in some cell populations. For example, a liganded TR $\alpha$ but not TR $\beta$ is required for such regulation in brain stem cells present in subventricular zone of the brain and for the migration of neuroblasts out of the stem cell niche (Lemkine et al., 2005).

\section{$\operatorname{Mdm} 2$}

$\mathrm{Mdm} 2$ is the best known inhibitor of p53. The binding of Mdm2 to p53 causes rapid p53 degradation by a proteasome-mediated process (Kubbutat et al., 1997) and inhibition of p53-mediated transactivation (Momand et al., 1992). This results in the reversal of p53-mediated cell cycle arrest (Chen et al., 1996). It is noteworthy that Mdm2 also interacts with other proteins involved in cell cycle regulation such as RB inhibiting its cell cycle-regulatory activity (Xiao et al., 1995), and with E2F1 stimulating its transcriptional activity (Martin et al., 1995). It also regulates transcriptional activity of cyclin A promoter (Leveillard \& Wasylyk, 1997). Therefore, Mdm2 not only releases a proliferative block by silencing p53, but also stimulates progression from the $G_{1}$ to the $S$ phase of the cell cycle by inhibiting RB activity and by stimulating E2F1.

Murine $m d m 2$ gene is activated by p53 that binds to its recognition site within the first intron of this gene. Two functionally active TREs were found within the same sequence (Zauberman et al., 1995; Qi et al., 1999). T3 treatment of TR-expressing GH$4 \mathrm{Cl}$ cells resulted in activation of endogenous $\mathrm{mdm} 2$ via these TREs (Qi et al., 1999). 


\section{INDIRECT REGULATION OF THE GENES ENCODING PROTEINS INVOLVED IN PROLIFERATION CONTROL BY T3}

cyclin D1

As mentioned before, cyclin $D 1$ gene encodes the regulatory subunit of a holoenzyme that phosphorylates and inactivates the RB protein and promotes progression through the $G_{1}$ phase of the cell cycle. However, recent analyses of knock-out mice lacking cyclins D revealed that these proteins are absolutely required for proliferation only in selected cell types (Kozar \& Sicinski, 2005). In addition, cyclin D1 associates with, and regulates activity of, transcription factors, coactivators, corepressors, and chromatin remodeling proteins. It also regulates cellular metabolism and migration (Fu et al., 2004.).

The first observations regarding the influence of T3 on cyclin D1 levels were made in neuroblastoma N2a- $\beta$ cells overexpressing TR $\beta 1$. Incubation of these cells with T3 resulted in a rapid decrease of cyclin D1 mRNA and protein levels (Perez-Juste \& Aranda, 1999). Similar effects were observed in mammary epithelial cells (Gonzalez-Sancho et al., 2002). Insights into the molecular mechanism of T3 action on cyclin D1 transcription were provided by experiments performed on N2a- $\beta$ cells. It has been shown that no classic TRE was present in cyclin D1 promoter. However, when the cyclic AMP response element (CRE) was deleted, T3-TR-mediated repression was completely abolished suggesting that it was executed via the binding to CRE-binding proteins CREB (CRE-binding protein) or ATF-2 (activation transcription factor 2). Since no change in the abundance of these proteins was detected, most possibly T3-TR complex altered not their expression, but their transactivation activity (Garcia-Silva \& Aranda, 2004).

It is noteworthy that the opposite was observed in rat pituitary growth hormone-producing GC cells where T3 treatment caused shortening of $\mathrm{G}_{1}$ phase of the cell cycle accompanied by the increase of mRNA and protein levels of cyclin D1, cyclin $\mathrm{E}$, and cdk2. In addition, kinase activities associated with cyclins D1 and E increased 4-fold upon T3 treatment leading to the increase of RB phosphorylation (Barrera-Hernandez et al., 1999). A very fast increase of cyclin D1 mRNA and protein levels upon T3 administration accompanied by accelerated DNA synthesis and a 20-fold increase in mitotic activity was also observed in hepatocytes (Pibiri et al., 2001) and in cardiomyocytes of adult rats, where it was accompanied by translocation of cyclin D1 into the nuclei (Ledda-Columbano et al., 2006). No molecular explanation of this phenomenon was presented.
c-Fos

The members of the Fos protein family might be divided in two groups, according to their ability to transform rodent fibroblasts: transforming (c-Fos and FosB) and non-transforming (Fra-1 and Fra-2) proteins. c-Fos and FosB contain multiple transactivation modules in their $\mathrm{N}$ - and C-terminal parts (Tulchinsky, 2000). They form dimers with Jun or ATF proteins, and as AP-1 transcription factor, regulate gene expression in response to cytokines, growth factors, stress signals, as well as to oncogenic stimuli. Contribution of AP-1 to cell fate in response to a given stimulus depends on the relative abundance of AP-1 subunits, the composition of AP-1 dimers, the cell type, and the cellular microenvironment (Hess et al., 2004).

In the presence of a physiological amount of T3 (1 nM) c-Fos mRNA and protein levels are reduced. Transactivation assays with reporter vector containing $c$-Fos promoter showed that promoter activity decreased by $50-60 \%$ after 8 h of T3 treatment. This effect was magnified in the presence of overexpressed $\operatorname{TR} \alpha$ in a ligand dependent manner. It is most likely that this effect was due to transcriptional interference of liganded TR with AP1 transcription activator whose recognition site is present in c-Fos promoter (Perez et al., 1993). This hypothesis was confirmed by the same authors who showed that the repression of c-Fos gene by TRs was exerted through transcriptional interference with the AP-1 binding site and the serum response element (SRE) of this promoter (Perez et al., 1994). In accordance with these data it has been shown the hypothyroidism was associated with a marked increase of c-fos mRNA in rat cardiomyocytes. This effect could be reversed by T3 replacement (Green et al., 1991).

However, other authors showed that T3 treatment triggered a rapid, transient, and strong stimulation of c-Fos and FosB mRNA expression in Schwann cells (but not in NIH-3T3 and $\mathrm{CHO}$ cell lines). This was accompanied by an increase of c-Fos protein amount. Functionally active TRs were indispensable for this to occur (Mercier et al., 2001).

\section{SUGGESTED REGULATION OF TRANSCRIPTION OF THE GENES ENCODING PROTEINS INVOLVED IN PROLIFERATION CONTROL BY T3 VIA YET UNKNOWN MECHANISMS}

\section{TGF- $\beta$}

Transforming growth factor- $\beta$ was initially identified and named on the basis of its ability to 
stimulate fibroblast growth in soft agar, but it is now the best-studied growth inhibitory protein. The TGF- $\beta$ superfamily of versatile cytokines consists of nearly 30 members. TGF- $\beta$ binds to a cellsurface receptor that activates Smad signal transduction pathways. Smads assemble multisubunit complexes that regulate transcription (Shi, 2001; Miyazawa et al., 2002). The members of the TGF- $\beta$ family exert many different effects depending on the type and state of the cell (Bachman \& Park, 2005). For example, TGF- $\beta$ can stimulate the proliferation of mesenchymal cells, but it can also act as a growth-inhibitory factor for epithelial, lymphatic, hematopoetic, and endothelial cells.

Treatment with T3 of hepatic HepG2 cells, stably expressing TRs, caused inhibition of their proliferation by arresting them at the transition point between $G_{1}$ and $S$ phases. In addition to other alterations, a stimulation of TGF- $\beta$ on mRNA level was observed. The activity of its promoter was enhanced by T3 up to 8-fold, but this effect was dependent on the presence of the active TRs. It has been also shown that TGF- $\beta$ neutralizing antibodies, and not control antibodies, could reverse anti-proliferative effect of T3 in HepG2 cells proving that this was TGF- $\beta$-mediated mechanism (Yen et al., 2006).

\section{Cip/Kip family}

As mentioned before, Cip/Kip family members inhibit cdk2 and are required for the assembly of cyclin D-cdk4, -cdk6 complexes, and progression of the cell cycle. The family is well conserved phylogenetically, suggesting its biological importance (Sherr, 2000; Vidal \& Koff, 2000).

It has been shown that the incubation of N2a- $\beta$ neuroblastoma cells with $\mathrm{T} 3$ resulted in a strong and long-lasting increase of p27 ${ }^{\mathrm{Kip} 1}$ mRNA amount suggesting a role for $\mathrm{T} 3$ in transcriptional regulation of its gene. However, no TRE was found in $\mathrm{p} 27^{\mathrm{Kip} 1}$ promoter. Interestingly, the p27 Kip1 protein half-life was lengthened in T3treated N2a- $\beta$ cells leading to its accumulation. This, in turn, increased the level of p27 ${ }^{\mathrm{Kip} 1}$-cdk2 complexes and led to a marked inhibition of the kinase activity of the cyclin E-cdk2 complexes. As a result, RB protein was hypophosphorylated and this caused cell cycle arrest (Perez-Juste \& Aran$\mathrm{da}, 1999)$. In hepatoma cells, the $\mathrm{p} 21^{\mathrm{Cip} 1}$ protein or mRNA levels were up-regulated 5-fold or 7-fold, respectively, following T3 treatment (Yen et al., 2006). In contrast, depletion of $\mathrm{T} 3$ induced $\mathrm{p} 21^{\mathrm{Cip} 1}$ expression in astrocytoma cells. This could be reversed by exogenous T3 (Toms et al., 1998).

Transient neonatal hypothyroidism resulted in prolonged postnatal Sertoli cell mitogenesis and doubled adult Sertoli cell numbers. p27Kip1 immunostaining was reduced in Sertoli cells from hypothyroid mice, while hyperthyroidism increased p27 ${ }^{\text {Kip1 }}$ immunostaining relative to controls from euthyroid animals, suggesting that T3 effects on Sertoli cells proliferation may be mediated by this protein (Holsberger et al., 2003). This result was confirmed by other authors who showed that T3 treatment induced an accumulation of p27 $7^{\mathrm{Kip} 1}$ and p21 ${ }^{\text {Cip1 }}$ in these cells (Buzzard et al., 2003). A similar observation was made in HepG2 cells where T3 treatment resulted in $\mathrm{p} 21^{\mathrm{Cip} 1} \mathrm{mRNA}$ and protein accumulation (Yen et al., 2006) and in N2a- $\beta$ cells where T3 treatment resulted in a strong and sustained increase of the levels of the p27 ${ }^{\text {Kip1 }}$ (GarciaSilva et al., 2002). This caused a marked inhibition of cyclin-cdk2 complexes, hypophosphorylation of $\mathrm{RB}$ and inhibition of the cell cycle progression. On the other hand, hyperthyroidism caused the decrease of p27 ${ }^{\text {Kip } 1}$ level in rat liver after partial hepatectomy (Alisi et al., 2005). The precise molecular mechanism of tissue specific $\mathrm{p} 27^{\mathrm{Kip} 1}$ and p21 ${ }^{\text {Cip } 1}$ regulation by T3 is not known.

\section{Epidermal growth factor (EGF) and its receptor (EGFR)}

EGF was one of the first growth stimulating peptides described. It has a characteristic structure with three disulfide bridges, which is essential for its activity (Carpenter \& Cohen, 1990; Van Zoelen et al., 2000). The receptor for EGF (EGFR or ErbB-1 or HER-1) is a member of the ErbB family of receptor tyrosine kinases. It is a cell-surface protein consisting of an extracellular ligand-binding domain, a single transmembrane region, and an intracellular domain with tyrosine kinase activity. Activation of the receptor occurs when a ligand, such as EGF or transforming growth factor- $\alpha$ binds to the ectodomain of the receptor, resulting in its dimerization, activation of the intracellular kinase domain, autophosphorylation, and activation of downstream signaling molecules (Yarden \& Sliwkowski, 2001).

The treatment of mouse submandibular gland cells by T3 resulted in a rapid increase of EGF mRNA and protein. In hypothyroid mice the amount of EGF mRNA in these cells was low and increased after T3 administration in a dose-dependent manner (Fujieda et al., 1993). T3 exposure led to a significant increase of EGF-promoted DNA synthesis in renal tubule cells. The level of EGFR mRNA markedly increased in proximal tubule cells upon treatment with this hormone. This was accompanied by increase of EGFR protein on the cell surface (Humes et al., 1992). 
A significant increase in the total tyrosine kinase activity measured in bovine thyroid cell protein extracts was induced by physiological concentrations of T3. Tyrosine phosphorylation of EGFR was significantly stimulated by this hormone. However, the level of EGFR protein was not changed by T3 treatment as determined by Western blot (Di Fulvio et al., 2000).

\section{INTERACTIONS OF THYROID HORMONE RECEPTORS WITH PROTEINS INVOLVED IN CELL CYCLE CONTROL}

p53

The tumor suppressor p53 is a short-lived phosphoprotein present in low amounts in the nuclei of normal cells. $p 53$ expression, protein level and activity are regulated in a cell cycle-dependent manner. It plays a central role in the protection against permanent DNA damage and other consequences of physiological stress (Cadwell \& Zambetti, 2001). When the DNA is damaged, p53 induces the expression of p21 ${ }^{\text {Cip } 1}$ and $G_{1}$ arrest. p53 either forms homotetramers that act as a transcription factors, or interacts with other proteins leading to the induction of cell cycle arrest or to the induction of apoptosis (Levine, 1997; North \& Hainaut, 2000). p53 inactivation (most commonly due to mutation) is considered a key event in human carcinogenesis.

A physical interaction between the DNA binding domain of TR $\beta 1$ and p53 was initially detected (Yap et al., 1996). Subsequently, it has been shown that DNA binding domain and the carboxy terminus of p53 were involved in this interaction (Barrera-Hernandez et al., 1998). TR $\beta 1$ increased the binding of p53 to its recognition sites in the promoters of target genes. This resulted in the repression of p53-dependent activation of certain genes such as bax and gadd45, while transcription of others was not affected (Barrera-Hernandez et al., 1998). Other authors show that overexpression of p53 blocks TR-mediated constitutive activation of transcription that is not dependent on the presence of $\mathrm{T} 3$, and suggest that this is due to the reversal of p53-mediated repression (Qi et al., 1997).

Thyroid hormones may influence the function of p53 by altering its expression, as shown in T47D human breast ductal carcinoma cell line where p53 amount increased in a T3 concentration-dependent manner (Dinda et al., 2002), or by affecting its posttranscriptional modification, as shown in T4-treated HEK293 and in HeLa cells that do not express TRs. Such treatment promoted p53 phosphorylation by mitogen-activated protein kinase (MAPK) (Shih et al., 2001).

\section{OTHER FUNCTIONS OF T3 IN CELL CYCLE CONTROL}

\section{Counteracting Ras-induced proliferation}

The Ras protooncogenes encode GTP-binding proteins $(\mathrm{H}-, \mathrm{K}-$, and $\mathrm{N}$-Ras) acting at the cellular membrane. Ras activate several pathways of signal transduction including the mitogenic Ras/mitogenactivated protein kinase (MAPK) pathway. While Ras has usually been regarded as a transforming oncogene, its activation in normal cells causes growth arrest via the induction of p53 and cyclin-dependent kinase inhibitors (Crespo \& Leon, 2000).

It has been shown that hypothyroidism was associated with a marked increase in myocardial $\mathrm{H}$ ras mRNA. This effect was reversed by T3 treatment. Administration of $\mathrm{T} 3$ to euthyroid rats resulted in inhibition of H-ras mRNA (Green et al., 1991).

T3 inhibits Ras-induced proliferation of neuroblastoma cells. This hormone is able to block the response to the oncogenic forms of all three Ras isoforms by interfering with the activity of the Ras/Erk/ Rsk pathway and CRE-mediated transcription (T3 inhibits transcriptional activity of b-Zip transcription factors such as CREB and ATF-2 that are direct targets of Rsk2), and both TR $\alpha$ and TR $\beta$ can mediate this action. As a result, Ras-dependent induction of cyclin D1 and of other genes containing CRE element in their promoters is markedly decreased in the presence of T3 (Garcia-Silva \& Aranda, 2004).

\section{Induction of secretion of mitogenic factors}

This effect of T3 was observed in the central nervous system. Cerebellar astrocytes and C6 glioma cells (immortalized glial cells with properties of both astrocytes and oligodendrocytes) treated with T3 secrete basic fibroblast growth factor, and, to a lesser extent, acidic fibroblast growth factor, tumor necrosis factor- $\beta$ and TGF- $\beta$ (Trentin et al., 2001). Cerebellar astrocytes also secrete EGF which directly induces neuronal proliferation (Martinez \& Gomes, 2002; Martinez \& Gomes, 2005).

\section{Acknowledgements}

This work was supported by the State Committee for Scientific Research grants 3P04A 01225 (M.P.K.) and 2P05A 12826 (A.N.).

\section{REFERENCES}

Alisi A, Demori I, Spagnuolo S, Pierantozzi E, Fugassa E, Leoni S (2005) Thyroid status affects rat liver regenera- 
tion after partial hepatectomy by regulating cell cycle and apoptosis. Cell Physiol Biochem 15: 69-76.

Amati B, Frank SR, Donjerkovic D, Taubert S (2001) Function of the c-Myc oncoprotein in chromatin remodeling and transcription. Biochim Biophys Acta 1471: M135M145.

Attwooll C, Lazzerini Denchi E, Helin K (2004) The E2F family: specific functions and overlapping interests. EMBO J 23: 4709-4716.

Baas D, Bourbeau D, Sarlieve LL, Ittel ME, Dussault JH, Puymirat J (1997) Oligodendrocyte maturation and progenitor cell proliferation are independently regulated by thyroid hormone. Glia 19: 324-332.

Bachman KE, Park BH (2005) Duel nature of TGF- $\beta$ signaling: tumor suppressor vs. tumor promoter. Curr Opin Oncol 17: 49-54.

Barrera-Hernandez G, Zhan Q, Wong R, Cheng SY (1998) Thyroid hormone receptor is a negative regulator in p53-mediated signaling pathways. DNA Cell Biol 17: 743-750.

Barrera-Hernandez G, Park KS, Dace A, Zhan Q, Cheng SY (1999) Thyroid hormone-induced cell proliferation in GC cells is mediated by changes in G1 cyclin/cyclin-dependent kinase levels and activity. Endocrinology 140: 5267-5274.

Bassett JH, Harvey CB, Williams GR (2003) Mechanisms of thyroid hormone receptor-specific nuclear and extra nuclear actions. Mol Cell Endocrinol 213: 1-11.

Bauer A, Mikulits W, Lagger G, Stengl G, Brosch G, Beug $H$ (1998) The thyroid hormone receptor functions as a ligand-operated developmental switch between proliferation and differentiation of erythroid progenitors. EMBO J 17: 4291-4303.

Bernal J (2005) Pathophysiology of thyroid hormone deficiency during fetal development. J Pediatr Endocrinol Metab 18 (Suppl 1): 1253-1256.

Bernard S, Eilers M (2006) Control of cell proliferation and growth by Myc proteins. Results Probl Cell Differ 42: 329-342.

Bianco AC, Salvatore D, Gereben B, Berry MJ, Larsen PR (2002) Biochemistry, cellular and molecular biology and physiological roles of the iodothyronine selenodeiodinases. Endocr Rev 23: 38-89.

Buzzard JJ, Wreford NG, Morrison JR (2003) Thyroid hormone, retinoic acid, and testosterone suppress proliferation and induce markers of differentiation in cultured rat Sertoli cells. Endocrinology 144: 3722-3731.

Cadwell C, Zambetti GP (2001) The effects of wild-type p53 tumor suppressor activity and mutant p53 gain-offunction on cell growth. Gene 277: 5-30.

Carpenter G, Cohen S (1990) Epidermal growth factor. J Biol Chem 265: 7709-7712.

Carr FE, Wong NC (1994) Characteristics of a negative thyroid hormone response element. J Biol Chem 269: 4175-4179.

Chatterjee VK, Lee JK, Rentoumis A, Jameson JL (1989) Negative regulation of the thyroid-stimulating hormone alpha gene by thyroid hormone: receptor interaction adjacent to the TATA box. Proc Natl Acad Sci USA 86: 9114-9118.

Chen JD, Evans RM (1995) A transcriptional co-repressor that interacts with nuclear hormone receptors. Nature 377: $454-457$.

Chen J, Wu X, Lin J, Levine AJ (1996) Mdm-2 inhibits the G1 arrest and apoptosis functions of the p53 tumor suppressor protein. Mol Cell Biol 16: 2445-2452.

Chen SL, Chang YJ, Wu YH, Lin KH (2003) Mitogen-activated protein kinases potentiate thyroid hormone re- ceptor transcriptional activity by stabilizing its protein. Endocrinology 144: 1407-1419.

Cheng SY (2000a) Multiple mechanisms for regulation of the transcriptional activity of thyroid hormone receptors. In Reviews in Endocrine and Metabolic Disorders (LeRoith D, ed) pp 9-18. Kluwer Academic, New York, NY.

Cheng SY (2004b) Abnormalities of nuclear receptors in thyroid cancer. Cancer Treat Res 22: 165-178.

Cheng SY (2005) Thyroid hormone receptor mutations and disease: beyond thyroid hormone resistance. Trends Endocrinol Metab 16: 176-182.

Cheng SY (2005) Isoform-dependent actions of thyroid hormone nuclear receptors: lessons from knockin mutant mice. Steroids 70: 450-454.

Cole MD, Nikiforov MA (2006) Transcriptional activation by the Myc oncoprotein. Curr Top Microbiol Immunol 302: 33-50.

Crespo P, Leon J (2000) Ras proteins in the control of the cell cycle and cell differentiation. Cell Mol Life Sci 57: 1613-1636.

Di Fulvio M, Coleoni AH, Pellizas CG, Masini-Repiso AM (2000) Tri-iodothyronine induces proliferation in cultured bovine thyroid cells: evidence for the involvement of epidermal growth factor-associated tyrosine kinase activity. J Endocrinol 166: 173-182.

Dinda S, Sanchez A, Moudgil V (2002) Estrogen-like effects of thyroid hormone on the regulation of tumor suppressor proteins, p53 and retinoblastoma, in breast cancer cells. Oncogene 21: 761-768.

Eckey M, Moehren U, Baniahmad A (2003) Gene silencing by the thyroid hormone receptor. Mol Cell Endocrinol 213: 13-22.

Foster MP, Montecino-Rodriguez E, Dorshkind K (1999) Proliferation of bone marrow pro-B cells is dependent on stimulation by the pituitary/thyroid axis. J Immunol 163: 5883-5890.

Francavilla A, Carr BI, Azzarone A, Polimeno L, Wang Z, Van Thiel DH, Subbotin V, Prelich JG, Starzl TE (1994) Hepatocyte proliferation and gene expression induced by triiodothyronine in vivo and in vitro. Hepatology 20: 1237-1241.

Fu M, Wang C, Li Z, Sakamaki T, Pestell RG (2004) Cyclin D1: normal and abnormal functions. Endocrinology 145: 5439-5447.

Fujieda M, Murata Y, Hayashi H, Kambe F, Matsui N, Seo H (1993) Effect of thyroid hormone on epidermal growth factor gene expression in mouse submandibular gland. Endocrinology 132: 121-125.

Garcia-Silva S, Aranda A (2004) The thyroid hormone receptor is a suppressor of ras-mediated transcription, proliferation, and transformation. Mol Cell Biol 24: 7514-7523.

Garcia-Silva S, Perez-Juste G, Aranda A (2002) Cell cycle control by the thyroid hormone in neuroblastoma cells. Toxicology 181/182: 179-182.

Geng Y, Eaton EN, Picon M, Roberts JM, Lundberg AS, Gifford A, Sardet C, Weinberg RA (1996) Regulation of cyclin E transcription by E2Fs and retinoblastoma protein. Oncogene 12: 1173-1180.

Gonzalez-Sancho JM, Figueroa A, Lopez-Barahona M, Lopez E, Beug H, Munoz A (2002) Inhibition of proliferation and expression of T1 and cyclin D1 genes by thyroid hormone in mammary epithelial cells. Mol Carcinog 34: 25-34.

Green NK, Gammage MD, Franklyn JA, Sheppard MC (1991) Regulation by thyroid status of c-myc, c-fos and H-ras mRNAs in the rat myocardium. J Endocrinol 130: 239-244. 
Harbour JW, Luo RX, Dei Santi A, Postigo AA, Dean DC (1999) Cdk phosphorylation triggers sequential intramolecular interactions that progressively block $\mathrm{Rb}$ functions as cells move through G1. Cell 98: 859-869.

Helin K (1998) Regulation of cell proliferation by the E2F transcription factors. Curr Opin Genet Dev 8: 28-35.

Hess J, Angel P, Schorpp-Kistner M (2004) AP-1 subunits: quarrel and harmony among siblings. J Cell Sci 117: $5965-5973$

Holsberger DR, Jirawatnotai S, Kiyokawa H, Cooke PS (2003) Thyroid hormone regulates the cell cycle inhibitor p27Kip1 in postnatal murine Sertoli cells. Endocrinology 144: 3732-3738.

Humes HD, Cieslinski DA, Johnson LB, Sanchez IO (1992) Triiodothyronine enhances renal tubule cell replication by stimulating EGF receptor gene expression. Am J Physiol 262: F540-F545.

Johnson DG, Schwarz JK, Cress WD, Nevins JR (1993) Expression of transcription factor E2F1 induces quiescent cells to enter S phase. Nature 365: 349-352.

Kamiya Y, Puzianowska-Kuznicka M, McPhie P, Nauman J, Cheng SY, Nauman A (2002) Expression of mutant thyroid hormone nuclear receptors is associated with human renal clear cell carcinoma. Carcinogenesis 23: 25-33.

Kassem M, Mosekilde L, Eriksen EF (1993) Effects of triiodothyronine on DNA synthesis and differentiation markers of normal human osteoblast-like cells in vitro. Biochem Mol Biol Int 30: 779-788.

Kozar K, Sicinski P (2005) Cell cycle progression without cyclin D-CDK4 and cyclin D-CDK6 complexes. Cell Cycle 4: 388-391.

Kubbutat MH, Jones SN, Vousden KH (1997) Regulation of p53 stability by Mdm2. Nature 387: 299-303.

Ledda-Columbano GM, Perra A, Pibiri M, Molotzu F, Columbano A (2005) Induction of pancreatic acinar cell proliferation by thyroid hormone. J Endocrinol 185: 393-399.

Ledda-Columbano GM, Molotzu F, Pibiri M, Cossu C, Perra A, Columbano A (2006) Thyroid hormone induces cyclin D1 nuclear translocation and DNA synthesis in adult rat cardiomyocytes. FASEB J 20: 87-94.

Lemkine GF, Raj A, Alfama G, Turque N, Hassani Z, Alegria-Prevot O, Samarut J, Levi G, Demeneix BA (2005) Adult neural stem cell cycling in vivo requires thyroid hormone and its alpha receptor. FASEB J 19: 863-865.

Leveillard T, Wasylyk B (1997) The MDM2 C-terminal region binds to TAFII250 and is required for MDM2 regulation of the cyclin A promoter. J Biol Chem 272: 30651-30661.

Levine AJ (1997) p53, the cellular gatekeeper for growth and division. Cell 88: 323-331.

Lin HY, Hopkins R, Cao HJ, Tang HY, Alexander C, Davis FB, Davis PJ (2005) Acetylation of nuclear hormone receptor superfamily members: thyroid hormone causes acetylation of its own receptor by a mitogen-activated protein kinase-dependent mechanism. Steroids 70: 444449.

Malik R, Mellor N, Selden C, Hodgson H (2003) Triiodothyronine enhances the regenerative capacity of the liver following partial hepatectomy. Hepatology 37: 79-86.

Manteuffel-Cymborowska M (1999) Nuclear receptors, their coactivators and modulation of transcription. Acta Biochim Polon 46: 77-89.

Martin K, Trouche D, Hagemeier C, Sorensen TS, La Thangue NB, Kouzarides T (1995) Stimulation of E2F1/
DP1 transcriptional activity by MDM2 oncoprotein. Nature 375: 691-694.

Martinez R, Gomes FC (2002) Neuritogenesis induced by thyroid hormone-treated astrocytes is mediated by epidermal growth factor/mitogen-activated protein kinasephosphatidylinositol 3-kinase pathways and involves modulation of extracellular matrix proteins. J Biol Chem 277: 49311-49318.

Martinez R, Gomes FC (2005) Proliferation of cerebellar neurons induced by astrocytes treated with thyroid hormone is mediated by a cooperation between cell contact and soluble factors and involves the epidermal growth factor-protein kinase a pathway. J Neurosci Res 80: 341-349.

Matsushime H, Ewen ME, Strom DK, Kato JY, Hanks SK, Roussel MF, Sherr CJ (1992) Identification and properties of an atypical catalytic subunit (p34PSK-J3/cdk4) for mammalian D type G1 cyclins. Cell 71: 323-334.

McKenna NJ, Lanz RB, O'Malley BW (1999) Nuclear receptor coregulators: cellular and molecular biology. Endocr Rev 20: 321-344.

Mercier G, Turque N, Schumacher M (2001) Rapid effects of triiodothyronine on immediate-early gene expression in Schwann cells. Glia 35: 81-89.

Meyerson M, Harlow E (1994) Identification of G1 kinase activity for cdk6, a novel cyclin D partner. Mol Cell Biol 14: 2077-2086.

Miyazawa K, Shinozaki M, Hara T, Furuya T, Miyazono K (2002) Two major Smad pathways in TGF-beta superfamily signalling. Genes Cells 7: 1191-1204.

Momand J, Zambetti GP, Olson DC, George D, Levine AJ (1992) The mdm-2 oncogene product forms a complex with the p53 protein and inhibits p53-mediated transactivation. Cell 69: 1237-1245.

Moore JM, Guy RK (2005) Coregulator interactions with the thyroid hormone receptor. Mol Cell Proteomics 4: 475-842.

Morreale de Escobar G, Obregon MJ, Escobar del Rey F (2004) Role of thyroid hormone during early brain development. Eur J Endocrinol 151 (Suppl 3): U25-U37.

North S, Hainaut P (2000) p53 and cell-cycle control: a finger in every pie. Pathol Biol 48: 255-270.

Nygard M, Wahlstrom GM, Gustafsson MV, Tokumoto YM, Bondesson M (2003) Hormone-dependent repression of the E2F-1 gene by thyroid hormone receptors. Mol Endocrinol 17: 79-92.

Ohmura T, Katyal SL, Locker J, Ledda-Columbano GM, Columbano A, Shinozuka H (1997) Induction of cellular DNA synthesis in the pancreas and kidneys of rats by peroxisome proliferators, 9-cis retinoic acid, and 3,3',5-triiodo-L-thyronine. Cancer Res 57: 795-798.

Onate SA, Tsai SY, Tsai MJ, O’Malley BW (1995) Sequence and characterization of coactivator for the steroid hormone receptor superfamily. Science 270: 1354-1357.

Palmero S, Prati M, Bolla F, Fugassa E (1995) Tri-iodothyronine directly affects rat Sertoli cell proliferation and differentiation. J Endocrinol 145: 355-362.

Perez P, Schonthal A, Aranda A (1993) Repression of c-fos gene expression by thyroid hormone and retinoic acid receptors. J Biol Chem 268: 23538-23543.

Perez P, Palomino T, Schonthal A, Aranda A (1994) Determination of the promoter elements that mediate repression of c-fos gene transcription by thyroid hormone and retinoic acid receptors. Biochem Biophys Res Commun 205: 135-140.

Perez-Juste G, Aranda A (1999) The cyclin-dependent kinase inhibitor p27(Kip1) is involved in thyroid hormone-mediated neuronal differentiation. J Biol Chem 274: 5026-5031. 
Perez-Juste G, Garcia-Silva S, Aranda A (2000) An element in the region responsible for premature termination of transcription mediates repression of c-myc gene expression by thyroid hormone in neuroblastoma cells. I Biol Chem 275: 1307-1314.

Pibiri M, Ledda-Columbano GM, Cossu C, Simbula G, Menegazzi M, Shinozuka H, Columbano A (2001) Cyclin D1 is an early target in hepatocyte proliferation induced by thyroid hormone (T3). FASEB J 15: 10061013.

Puzianowska-Kuznicka M, Krystyniak A, Madej A, Cheng SY, Nauman J (2002) Functionally impaired thyroid hormone receptor mutants are present in thyroid papillary cancer. J Clin Endocrinol Metab 87: 1120-1128.

Qi JS, Desai-Yajnik V, Yuan Y, Samuels HH (1997) Constitutive activation of gene expression by thyroid hormone receptor results from reversal of p53-mediated repression. Mol Cell Biol 17: 7195-7207.

Qi JS, Yuan Y, Desai-Yajnik V, Samuels HH (1999) Regulation of the mdm2 oncogene by thyroid hormone receptor. Mol Cell Biol 19: 864-872.

Radoja N, Diaz DV, Minars TJ, Freedberg IM, Blumenberg M, Tomic-Canic M (1997) Specific organization of the negative response elements for retinoic acid and thyroid hormone receptors in keratin gene family. I Invest Dermatol 109: 566-572.

Rastinejad F (2001) Retinoid X receptor and its partners in the nuclear receptor family. Curr Opin Struct Biol 11: 33-38.

Sadow PM, Chassande O, Gauthier K, Samarut J, Xu J, O'Malley BW, Weiss RE (2003) Specificity of thyroid hormone receptor subtype and steroid receptor coactivator-1 on thyroid hormone action. Am J Physiol Endocrinol Metab 284: E36-E46.

Safer JD, Crawford TM, Holick MF (2005) Topical thyroid hormone accelerates wound healing in mice. Endocrinology 146: 4425-4430.

Sakurai A, Nakai A, DeGroot LJ (1989) Expression of three forms of thyroid hormone receptor in human tissues. Mol Endocrinol 3: 392-399.

Sasaki S, Lesoon-Wood LA, Dey A, Kuwata T, Weintraub BD, Humphrey G, Yang WM, Seto E, Yen PM, Howard $\mathrm{BH}$, Ozato K (1999) Ligand-induced recruitment of a histone deacetylase in the negative-feedback regulation of the thyrotropin $\beta$ gene. EMBO J 18: 5389-5398.

Schrader M, Carlberg C (1994) Thyroid hormone and retinoic acid receptors form heterodimers with retinoid $X$ receptors on direct repeats, palindromes and inverted palindromes. DNA Cell Biol 13: 333-341.

Shahrara S, Drvota V, Sylven C (1999) Organ specific expression of thyroid hormone receptor mRNA and protein in different human tissues. Biol Pharm Bull 22: 1027-1033.

Sherr CJ (1993) Mammalian G1 cyclins. Cell 73: 1059-1065.

Sherr CJ (2000) The Pezcoller lecture: cancer cell cycles revisited. Cancer Res 60: 3689-3695.

Sherr CJ, Roberts JM (2004) Living with or without cyclins and cyclin-dependent kinases. Genes Dev 18: 26992711.

Shi Y (2001) Structural insights on Smad function in TGFbeta signaling. Bioessays 23: 223-232.

Shibusawa N, Hollenberg AN, Wondisford FE (2003) Thyroid hormone receptor DNA binding is required for both positive and negative gene regulation. J Biol Chem 278: 732-738.
Shih A, Lin HY, Davis FB, Davis PJ (2001) Thyroid hormone promotes serine phosphorylation of p53 by mitogen-activated protein kinase. Biochemistry 40: 28702878.

Su Y, Damjanovski S, Shi Y, Shi YB (1999) Molecular and cellular basis of tissue remodeling during amphibian metamorphosis. Histol Histopathol 14: 175-183.

Szanto A, Narkar V, Shen Q, Uray IP, Davies PJ, Nagy L (2004) Retinoid $X$ receptors: X-ploring their (patho)physiological functions. Cell Death Differ 11 (Suppl 2): S126-S143.

Toms SA, Hercbergs A, Liu J, Kondo S, Barnett GH, Casey G, Barna BP (1998) Thyroid hormone depletion inhibits astrocytoma proliferation via a p53-independent induction of p21 (WAF1/CIP1). Anticancer Res 18: 289-293.

Trentin AG, Alvarez-Silva M, Moura Neto V (2001) Thyroid hormone induces cerebellar astrocytes and C6 glioma cells to secrete mitogenic growth factors. Am J Physiol Endocrinol Metab 281: E1088-E1094.

Tulchinsky E (2000) Fos family members: regulation, structure and role in oncogenic transformation. Histol Histopathol 15: 921-928.

Weiss RE, Ramos HE (2004) Thyroid hormone receptor subtypes and their interaction with steroid receptor coactivators. Vitam Horm 68: 185-207.

Williams GR, Robson H, Shalet SM (1998) Thyroid hormone actions on cartilage and bone: interactions with other hormones at the epiphyseal plate and effects on linear growth. J Endocrinol 157: 391-403.

Wolffe AP, Collingwood TN, Li Q, Yee J, Urnov F, Shi YB (2000) Thyroid hormone receptor, v-ErbA, and chromatin. Vitam Horm 58: 449-492.

Wu L, Timmers C, Maiti B, Saavedra HI, Sang L, Chong GT, Nuckolls F, Giangrande P, Wright FA, Field SJ, Greenberg ME, Orkin S, Nevins JR, Robinson ML, Leone G (2001) The E2F1-3 transcription factors are essential for cellular proliferation. Nature 414: 457-462.

Van Zoelen EJ, Stortelers C, Lenferink AE, Van de Poll ML (2000) The EGF domain: requirements for binding to receptors of the ErbB family. Vitam Horm 59: 99-131.

Vidal A, Koff A (2000) Cell-cycle inhibitors: three families united by a common cause. Gene 247: 1-15.

Xiao ZX, Chen J, Levine AJ, Modjtahedi N, Xing J, Sellers WR, Livingston DM (1995) Interaction between the retinoblastoma protein and the oncoprotein MDM2. Nature 375: 694-698.

Yap N, Yu CL, Cheng SY (1996) Modulation of the transcriptional activity of thyroid hormone receptors by the tumor suppressor p53. Proc Natl Acad Sci USA 93: 4273-4277.

Yarden Y, Sliwkowski MX (2001) Untangling the ErbB signalling network. Nat Rev Mol Cell Biol 2: 127-137.

Yen PM, Cheng SY (2003) Germline and somatic thyroid hormone receptor mutations in man. J Endocrinol Invest 26: 780-787.

Yen CC, Huang YH, Liao CY, Liao CJ, Cheng WL, Chen WJ, Lin KH (2006) Mediation of the inhibitory effect of thyroid hormone on proliferation of hepatoma cells by transforming growth factor-beta. J Mol Endocrinol 36: 9-21.

Zhang J, Lazar MA (2000) The mechanism of action of thyroid hormones. Annu Rev Physiol 62: 439-466. 